\title{
Chronic Supplementation of Melatonin restores Impaired Circadian Rhythm in Patients with Coronary Artery Disease
}

\author{
${ }^{1}$ Shipra Bhardwaj, ${ }^{2}$ Narsingh Verma, ${ }^{3}$ VS Narain, ${ }^{4}$ Vinod Kumar, ${ }^{5}$ Kshitij Bhardwaj, ${ }^{6}$ Saumya Mishra
}

\begin{abstract}
Blood pressure (BP) has a characteristic and reproducible circadian pattern with high values during the day and low values at night. Previous studies have shown that in patients with coronary artery disease (CAD), the nocturnal dip of BP is absent or blunted, which may be correlated to the reduced melatonin levels or altered melatonin-cortisol interplay. Our objective was to assess the effect of bedtime melatonin administration on circadian pattern of BP and heart rate $(H R)$ in CAD patients. One hundred CAD patients were recruited for the study. General health records were individually maintained. Each study participant was given a $5 \mathrm{mg}$ pure melatonin supplement each night at bedtime for a period of 1 year. A 24 hour/7 day ambulatory blood pressure monitoring (ABPM) using ambulatory blood pressure monitor and serum melatonin level estimations were done initially, after 6 months, and after 1 year of melatonin supplementation. The rhythmic parameters of systolic $\mathrm{BP}$ (SBP) and diastolic BP (DBP), HR, viz. midline-estimating statistic of rhythm (MESOR), double amplitude, acrophase, 3 hour fractionated hyperbaric index $(\mathrm{HBI})$ were significantly reduced and serum melatonin concentration significantly increased after 6 and 12 months of exogenous melatonin supplementation. Circadian hyperamplitude tension (CHAT) incidence decreased as melatonin treatment progressed. The number of subject diagnosed with CHAT was as follows: $37 / 100$ at the beginning, 17/100 after 6 months, and 6/100 after 12 months. These data suggest that $5 \mathrm{mg} /$ day melatonin treatment improved and restored the circadian pattern of BP in CAD subjects.
\end{abstract}

Keywords: Ambulatory blood pressure monitoring, Circadian hyperamplitude tension, Coronary artery disease, Hyperbaric index, Melatonin.

How to cite this article: Bhardwaj S, Verma N, Narain VS, Kumar V, Bhardwaj K, Mishra S. Chronic Supplementation of Melatonin restores impaired Circadian Rhythm in Patients with Coronary Artery Disease. Hypertens J 2017;3(2):94-100.

Source of support: Nil

Conflict of interest: None

${ }^{1,6}$ Research Scientist, ${ }^{2-4}$ Professor, ${ }^{5}$ Scientist

${ }^{1}$ Department of Radiation Oncology, Dr Ram Manohar Lohia Institute of Medical Sciences, Lucknow, Uttar Pradesh, India

2,5Department of Physiology, King George Medical University Lucknow, Uttar Pradesh, India

${ }^{3}$ Department of Cardiology, King George Medical University Lucknow, Uttar Pradesh, India

${ }^{4}$ Department of Zoology, University of Delhi, New Delhi, India

${ }^{6}$ Department of Medicine, King George Medical University Lucknow, Uttar Pradesh, India

Corresponding Author: Narsingh Verma, Professor, Department of Physiology, King George Medical University, Lucknow, Uttar Pradesh, India, e-mail: narsinghverma@gmail.com

\section{INTRODUCTION}

Most physiological parameters exhibit circadian rhythms reflecting an innate temporal program provided by biological clocks. Chronobiological studies include but are not limited to comparative anatomy, physiology, genetics, molecular biology, and behavior of organisms within biological rhythms mechanics. Systemic BP has a characteristic and reproducible daily pattern, as regulated by the circadian timing system. ${ }^{1,2}$ In most people, BP drops by 10 to $20 \%$ during night are called dippers; those in whom such reductions are not present appear to be at increased risk for cardiovascular events and these peoples are called nondippers. In addition, it was reported that in people whose 24-hour BP exceeded 135/85 mm Hg, were nearly twice as likely to have a cardiovascular event as those with 24-hour mean BPs $<135 / 85 \mathrm{~mm} \mathrm{Hg}$, irrespective of the level of the office $\mathrm{BP} .^{3}$ The regular cycle of $\mathrm{BP}$ is important especially because an inverted daily pattern with higher $\mathrm{BP}$ values during the night and lower during the day is associated with an increased target organ damage (in cardiac, cerebral, vascular, and renal tissues) and worsened cardiovascular outcome. Patients with $C A D$, a major complication of chronic hypertension, show a blunted day-night rhythm in vasodilatation and suppressed or attenuated night-time melatonin levels, ${ }^{4}$ and thus the normal dipping pattern of BP is absent or disturbed. ${ }^{4,5,8,9}$ Melatonin is a circadian clock-regulated hormone produced largely from the pineal gland. Mounting evidence reveals that the rhythmicity of melatonin has a crucial role in a variety of cardiovascular pathophysiological processes including anti-inflammatory, antioxidant, and antihypertensive and, possibly, antilipidemic functions. ${ }^{6,7}$ Normally, melatonin levels are low during the day and high at night. ${ }^{6} \mathrm{~A}$ possible link between melatonin and circulation is suggested by the following: (i) The rhythms in melatonin and cardiovascular activity have inverse phase relationship. The nocturnal rise in melatonin coincides with the declined cardiovascular activity. (ii) In experimental animals, melatonin is shown to prevent ischemia and/or reperfusion-induced cardiac arrhythmias, influence BP control, ${ }^{10,11}$ regulate blood flow to the brain, ${ }^{12}$ and modify peripheral artery responsiveness to norepinephrerine. ${ }^{13}$ A melatonin supplement at night increases endogenous melatonin levels and hence, helps to protect from cardiovascular diseases. ${ }^{14}$ Zonobani A et al (1978) 
further suggested that melatonin by its action on the suprachiasmatic nucleus (SCN), the circadian clock influences the autonomic output to the cardiovascular system ${ }^{15}$ and in turn improves the circadianly regulated autonomic regulation of BP in hypertensive patients. Hence, it can be reasoned that low melatonin levels are linked with the impairment of the cardiovascular functioning. In humans, melatonin production not only diminishes with age, but also lowers in many age-related diseases, including cardiovascular disease. ${ }^{16,17}$ Coronary artery disease patients show a markedly decreased nighttime melatonin synthesis, ${ }^{17}$ which may be assumed reason for absence of nocturnal dip in BP and high chances of myocardial infarction. ${ }^{5}$ In addition, light/dark variations in the production of endogenous inflammatory markers in patients with CAD to some extent may be related to day/night fluctuations in circulating melatonin levels. ${ }^{6}$ Melatonin secreted from pineal gland and controlled by SCN plays a vital role in maintaining normal circadian pattern ${ }^{18}$ and also in autonomic regulation of cardiovascular system. ${ }^{19}$ There is a growing body of evidence suggesting that a blunted decrease in nighttime $\mathrm{BP}$ is associated with a greater risk of target organ damage. It has been suggested that impairment of the sympathetic nervous system may contribute to the attenuation of the nocturnal BP dip. ${ }^{20}$ However, the mechanisms underlying this abnormal nighttime BP dipping pattern are not fully understood. ${ }^{16}$ There is some evidence suggesting that a nondipping BP pattern may be related to advanced age ${ }^{21}$ sodium sensitivity, ${ }^{22}$ postmenopausal status, ${ }^{20}$ sleep apnea, and poor sleep quality. ${ }^{21}$ Some studies state that melatonin supplementation at certain times during the night may function to increase endogenous melatonin level, potentially protecting against the melatonin downregulation associated with cardiovascular diseases. ${ }^{44,47}$ Because melatonin via SCN influences the autonomic output to the cardiovascular system, ${ }^{15}$ restoration of proper functioning of the SCN in patients with hypertension could improve the autonomic regulation of BP. In this study, we used a 7 day timed analysis of the records of BP through ABPM to diagnose day-to-day variability, $^{23}$ which is termed as CHAT, a condition in which excessive circadian BP amplitude precedes chronic established hypertension. ${ }^{24}$ We therefore, investigated in a 1 year study the effect of bedtime melatonin supplementation on the circadian pattern of BP in patients with CAD and established the clinical implications of it on 24 hours $/ 7$ days rhythmic pattern of BP in CAD patients.

\section{MATERIALS AND METHODS}

\section{Registration of Volunteer Patients of CAD}

One hundred patients of CAD diagnosed by invasive or noninvasive techniques at King George Medical University, Lucknow, India, were registered for the present study.
The protocol of this study was approved by the Committee of medical Ethics, Research cell CSMMU (3118/R.Cell-08), Lucknow, in compliance with the declaration of Helsinki principles of medical ethics. All the subjects were explained about the purpose and protocols of the study before obtaining written informed consent from each of them in English and Hindi languages. Statistical significance between initial, 6-month and 1-year experimental values was compared for analysis. No separate control group was recruited to avoid any medical/pathophysiological changes during statistical comparisons.

\section{Treatment}

All study participants took $5 \mathrm{mg}$ melatonin as supplement, orally before sleep for a period of 1 year. The supplement was pure melatonin procured from Marc Laboratories, Himachal Pradesh, India. All study participants were allowed to continue their ongoing treatment.

\section{Monitoring of Health Records}

The health records of each subject were maintained during the entire period of treatment with general observations, like the presence or absence of headache, insomnia, hyperactivity, irritability, nausea, sleeping limbs, dizziness, constipation, shaky hands, stomach cramp, drowsiness, sweating, hunger, weakness, and sore eyes. The participants were instructed to report immediately in case they developed symptom(s) of any of these diseases, and advised to discontinue the oral intake of melatonin.

\section{Ambulatory Blood Pressure Monitoring}

A 24 hour/7 day ABPM of the subjects was done with an automated ABPM device, A\&D TM-2430 (A\&D Company, Japan). The ABPM of each subject was done three times before and after 6 and 12 months of the oral melatonin supplement. Participants were told to carry out all their routine works during recording periods. The machine was programmed to record $\mathrm{BP}$ and $\mathrm{HR}$ taken every 30 minutes during the day and after 1 hour interval during the night. Measurements from the ABPM device were transferred and stored in the computer for further analysis. For each individual, the data were summarized in a sphygmochron (a computer comparison of patients' profile with the specified reference limit). The results were analyzed using Halberg Cosinor analysis. Each BP and HR profile was analyzed by a sphygmochron, utilizing both a parametric and nonparametric approach. Ambulatory blood pressure monitoring records were sent to Halberg Chronobiology Center, University of Minnesota, and Minneapolis, USA, for further interpretation. The following estimates were obtained: (i) MESOR, a time structure 
Table 1: Clinical characteristics and observation of CAD subjects enrolled for the study

\begin{tabular}{llll}
\hline Clinical characteristics & Males & Females & All subjects \\
\hline No. of subjects & 69 & 31 & 100 \\
Age (years; mean \pm SE) & $62.2 \pm 13.4$ & $58 \pm 10.44$ & $65.44 \pm 13.54$ \\
Height $(\mathrm{cm}$; mean $\pm \mathrm{SE})$ & $173.73 \pm 4.52$ & $158.49 \pm 4.38$ & $170.25 \pm 9.42$ \\
Weight $(\mathrm{kg}$; mean $\pm \mathrm{SE})$ & $62.32 \pm 8.26$ & $59.68 \pm 7.22$ & $60.26 \pm 8.35$ \\
BMI $\left(\mathrm{kg} / \mathrm{m}^{2}\right.$; mean $\left.\pm \mathrm{SE}\right)$ & $22.37 \pm 2.50$ & $20.17 \pm 1.89$ & $25.56 \pm 3.53$ \\
Casual SBP $(\mathrm{mm}$ Hg; mean $\pm \mathrm{SE})$ & $142.21 \pm 12.32$ & $139.35 \pm 6.23$ & $140 \pm 11.20$ \\
Casual DBP (mm Hg; mean $\pm \mathrm{SE})$ & $88.26 \pm 7.1$ & $85.63 \pm 2.33$ & $87.63 \pm 3.66$ \\
Casual heart beats (bpm; mean $\pm \mathrm{SE})$ & $85 \pm 11$ & $92 \pm 9$ & $87 \pm 11$ \\
\hline
\end{tabular}

Values represent the mean \pm SE of 100 subjects; SE: Standard error

or chronome-adjusted mean; ${ }^{25}$ (ii) double amplitude or predictable change, which is the total change within a day or the circadian amplitude of reproducible variability within a day, (iii) acrophase, which is a measure of timing of overall high values recurring in each cycle; (iv) CHAT. The average 7-day values of the MESOR, double amplitude, acrophase, and 3-hour fractionated HBI for SBP, DBP, and $\mathrm{HR}$ were determined for each subject at all the three recordings, i.e., initial, after 6 and 12 months. The CHAT was diagnosed in subjects who were having larger-thanusual change in BP, and overswinging BP pattern in the double amplitude which precedes an overall elevation in $\mathrm{BP}$ and is an indication or predictor of a great risk of essential hypertension and CAD.

\section{Serum Melatonin Estimation}

Blood samples of CAD subjects were collected between 8:00 and 10:00 AM for the estimation of serum melatonin levels by enzyme-linked immunosorbent assay kit procured from IBL International, Germany.

\section{Statistics}

Statistical significance between initial, 6 months and 1 year experimental values of ABPM were calculated by Halberg Cosinor analysis and Student's t-test, ${ }^{9,25-27}$ whereas melatonin hormone analysis was calculated by Student's t-test only.

\section{RESULTS}

\section{Clinical Observations}

Twenty of the 120 patients dropped out of the study. There were 69 males and 31 female subjects (mean age 60.44 years). Mean SBP/DBP of the subjects recorded by mercury sphygmomanometer was $140 \pm 11.20 / 87.63 \pm$ 3.66. Mean HR was $87.63 \pm 3.66$ bpm (Table 1).

\section{Ambulatory Blood Pressure Monitoring}

\section{Midline-estimating Statistic of Rhythm}

There was significant difference between the baseline MESOR of SBP, DBP, and HR after 6 months and 1 year of the supplementation of melatonin in CAD subjects. In
CAD patients, baseline SBP/DBP was $142.07 \pm 1.18 / 92.40$ \pm 2.77 , which was significantly reduced to $133.03 \pm 4.36$ after 1 year of melatonin supplementation. Melatonin significantly reduced SBP. A 3\% decrease was noted after 6 months and $6.3 \%$ decrease was noted after 1 year of melatonin supplementation. The decrease of $3.3 \%$ after 6 months and $8.2 \%$ after 1 year was observed in DBP. There was a $5.58 \%$ decrease after 6 months and 9.63\% decrease after 1 year in MESOR HR, which was highly significant (Table 2 and Graph 1).

\section{Double Amplitude (Predictable Change)}

The circadian amplitude of reproducible variability also decreased significantly after 6 months and 1 year of the supplementation of melatonin in CAD subjects. There

Table 2: MESOR of 24 hours/ 7 days ABPM in CAD subjects initially and after 6 months and 1 year of melatonin supplementation

\begin{tabular}{|c|c|c|c|}
\hline & Initial & 6 months & 1 year \\
\hline $\mathrm{SBP}(\mathrm{mm} \mathrm{Hg})$ & $142.07 \pm 1.18$ & $\begin{array}{l}136.70 \pm 2.86^{*} \\
(p<0.05)\end{array}$ & $\begin{array}{l}133.03 \pm 4.36^{*} \Delta \\
(p<0.01)\end{array}$ \\
\hline $\mathrm{DBP}(\mathrm{mm} \mathrm{Hg})$ & $92.40 \pm 2.77$ & $\begin{array}{l}88.86 \pm 6.84^{*} \\
(p<0.05)\end{array}$ & $\begin{array}{l}84.82 \pm 7.63^{*} \Delta \\
(p<0.01)\end{array}$ \\
\hline HR (bpm) & $83.592 \pm 0.94$ & $\begin{array}{l}78.92 \pm 0.612^{*} \\
(p<0.05)\end{array}$ & $\begin{array}{l}75.05 \pm 0.358^{*} \Delta \\
(p<0.01)\end{array}$ \\
\hline
\end{tabular}

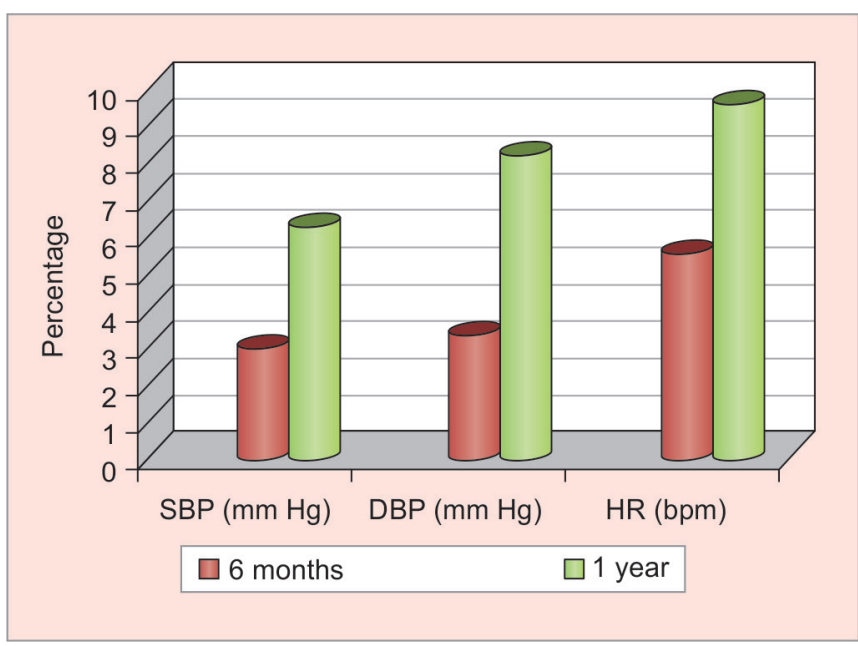

Graph 1: Percent decrease in MESOR of SBP, DBP, and HR after 6 months and 1 year of melatonin supplementation in CAD subjects 
Chronic Supplementation of Melatonin restores Impaired Circadian Rhythm

Table 3: Double amplitude (predictable change) of 24 hours/7 days ABPM in CAD subjects initially and after 6 months and 1 year of melatonin supplementation

\begin{tabular}{|c|c|c|c|}
\hline & Initial & 6 months & 12 months \\
\hline $\mathrm{SBP}(\mathrm{mm} \mathrm{Hg})$ & $28.04 \pm 0.98$ & $\begin{array}{l}23.14 \pm 0.91^{*} \Delta \\
(p<0.01)\end{array}$ & $\begin{array}{l}20.91 \pm 0.79^{*} \Delta \\
(p<0.01)\end{array}$ \\
\hline $\mathrm{DBP}(\mathrm{mm} \mathrm{Hg})$ & $19.68 \pm 0.84$ & $\begin{array}{l}17.94 \pm 0.61^{*} \\
(p<0.05)\end{array}$ & $\begin{array}{l}13.04 \pm 0.65^{*} \Delta \\
(p<0.01)\end{array}$ \\
\hline $\mathrm{HR}$ (bpm) & $16.66 \pm 0.697$ & $\begin{array}{l}12.95 \pm 0.98^{*} \Delta \\
(p<0.01)\end{array}$ & $\begin{array}{l}10.57 \pm 0.46^{*} \Delta \\
(p<0.05)\end{array}$ \\
\hline
\end{tabular}

*Significant at the level of $p<0.05 ; \Delta$ Significant at the level of $p<0.01$

was $10 \%$ decrease in SBP, $20 \%$ in DBP, and $10 \%$ decrease in HR after supplementation (Table 3 and Graph 2).

\section{Circadian Hyperamplitude Tension}

Circadian hyperamplitude tension (CHAT) was diagonsed in 37/100 subjects. After 6 months and 1 year of melatonin supplementation, CHAT was demonstrated in 17 and 6 cases respectively ( $p=0.05$; Graph 3$)$.

\section{Acrophase}

There were no statistically significant changes in acrophase of initial, 6, and 12 months ABPM of CAD subjects. However, the circadian pattern of timing of overall high values recorded at baseline (SBP/DBP 14:51 \pm 0.23/15:20 \pm $0.92)$ recurring in each cycle shifted toward normal (SBP/ DBP 16:33 $\pm 1.14 / 13: 41 \pm 0.22$ ) after 12 months of supplementation of melatonin. There was no significance difference between the initial and 12 months supplementation values of acrophase of HR (Table 4).

\section{Serum Melatonin}

Significant increase in serum melatonin levels was noted after 6 and 12 months of melatonin supplementation.

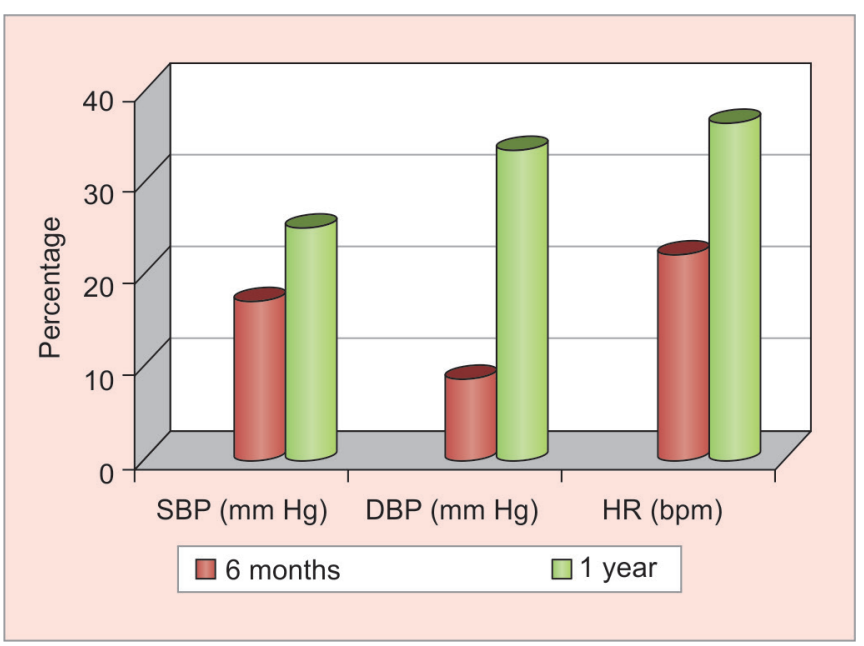

Graph 2: Percent decrease in double amplitude (predictable change) of SBP, DBP, and HR after 6 months and 1 year of melatonin supplementation in CAD subjects
Table 4: Acrophase of 24 hours/7 days ABPM in CAD subjects initially and after 6 and 12 months of melatonin supplementation

\begin{tabular}{llll}
\hline & Initial & 6 months & 12 months \\
\hline $\begin{array}{l}\text { SBP, mm Hg } \\
\text { (hh:mm:ss) }\end{array}$ & $14: 51 \pm 0.233$ & $15: 54 \pm 0.141$ & $16: 33 \pm 1.14$ \\
$\begin{array}{l}\text { DBP, mm Hg } \\
\text { (hh:mm:ss) }\end{array}$ & $15: 20 \pm 0.92$ & $14: 50 \pm 0.206$ & $13: 41 \pm 0.228$ \\
$\begin{array}{l}\text { HR, bpm } \\
\text { (hh:mm:ss) }\end{array}$ & $15: 45 \pm 0.43$ & $14: 20 \pm 0.215$ & $15: 24 \pm 0.207$ \\
\hline $\begin{array}{l}\text { Values represent the mean } \pm \text { standard error of } 100 \text { subjects at } \\
\text { each time interval }\end{array}$
\end{tabular}

Graph 4A shows the total increase in serum melatonin level and Graph $4 \mathrm{~B}$ shows the effect of serum melatonin levels on the SBP, DBP, and HR.

\section{DISCUSSION}

Baseline observation of our study shows that CAD patients had disturbed circadian pattern of 24 hours/ 7 days ambulatory $\mathrm{BP}$, which were restored or improved after they took melatonin as supplement. One year of melatonin as supplementation significantly reduced $\mathrm{ABP}$ and increased serum melatonin level (Table 2 and Graph 1). A reduction of $3 \mathrm{~mm} \mathrm{Hg}$ of systolic MESOR was observed after 6 months, which was further decreased to about $9 \mathrm{~mm}$ Hg after 12 months. Similarly, after 12 months, DBP was reduced to 4 to $7 \mathrm{~mm} \mathrm{Hg}$ and MESOR HR was reduced to 5 to $8 \mathrm{bpm}$. This is consistent with the previous reports that melatonin repeatedly given orally or intranasally can reduce $B P$ with essential hypertension. ${ }^{28,29}$ However, none of the subjects had complained of headache, palpitation, dyspnea, nausea, tremors, dizziness, sore eyes. There was initially high BP amplitude in $35 \%$ of our CAD subjects (Graph 3), which is the predictor of the CHAT and vascular disease risk associated with it. ${ }^{25,30}$ We found

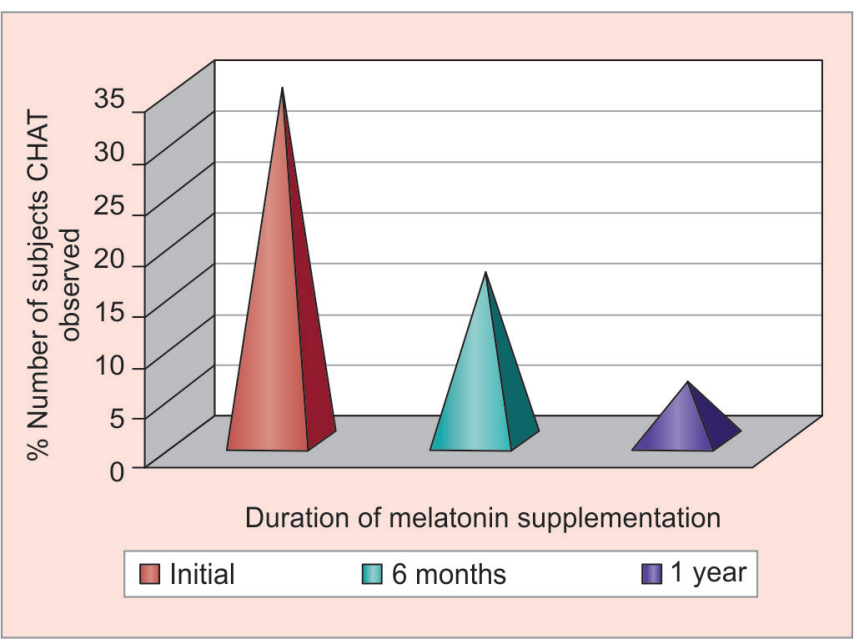

Graph 3: Percentage of number of subjects in whom CHAT was diagnosed during ABPM $(n=100)$ 


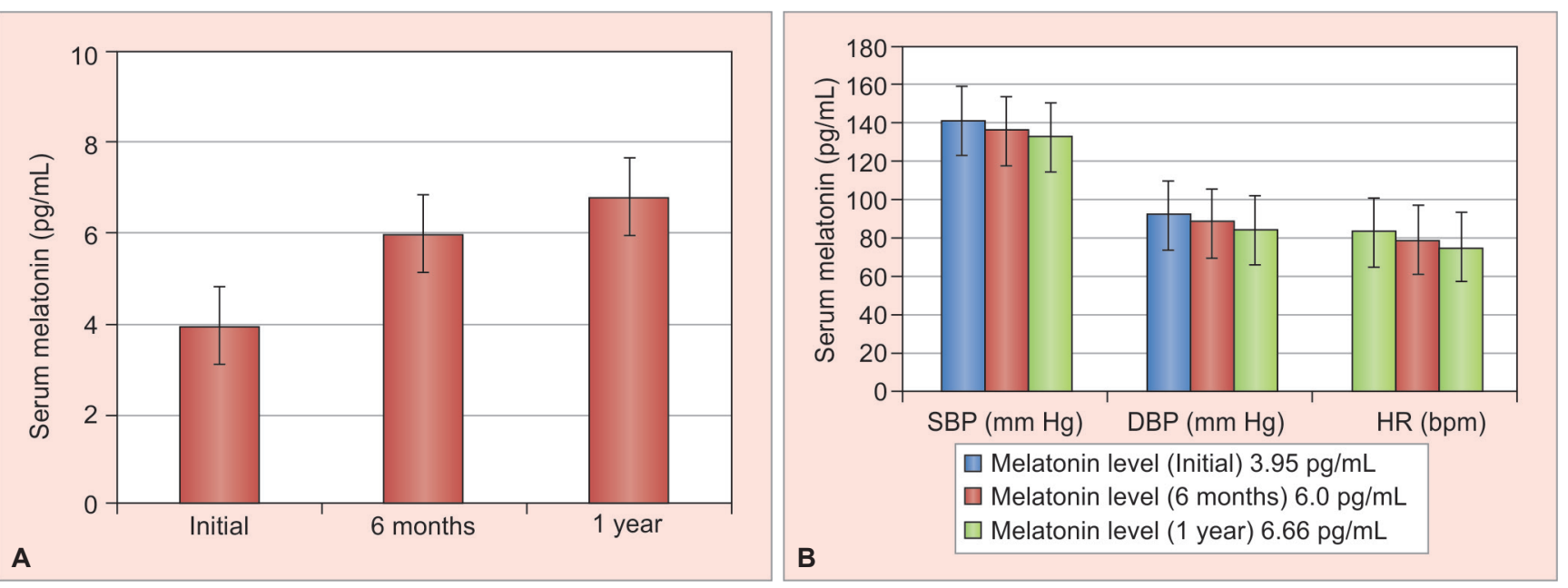

Graphs 4A and B: (A) Total increase in serum melatonin level; and (B) effect of serum melatonin levels on the SBP, DBP, and HR

that after 6 and 12 months of the melatonin supplement, CHAT was reduced to 17 and $6 \%$ respectively, and nondipping pattern shifted toward dipping. Recent findings of Rechciński et $\mathrm{al}^{31}$ also suggest nocturnal decline in BP of CAD patients, but there was also a nonoptimal increase in the daytime BP. We have found that melatonin given as supplement causes nocturnal decline in ambulatory dipping pattern without a nonoptimal increase in the daytime BP. There was no significant difference between the acrophases (time of excess) of BP and HR before and after the melatonin supplement. Circadian rhythm of acrophases (high values) lie at an interval of 12 to 20 hours, and batyphases (lowest values) at an interval of 2 to 6 hours. ${ }^{32}$ Similar pattern was observed in the acrophase (Table 4) of subjects after 12 months of oral melatonin, suggesting the synchronizing role of melatonin for daily BP rhythms. Our results indicated a significant increase in serum melatonin concentrations of CAD subjects after 6 and 12 months of melatonin supplementation. However, initial observation in same subjects indicated low levels of serum melatonin. Low levels of melatonin in CAD subjects have also been already reported. ${ }^{5,33}$ The rise in serum levels of endogenous melatonin of CAD subjects after melatonin supplement may be due to the improvisation of SCN autonomic activity possessed by exogenous melatonin supplementation. Previously Laakso et $\mathrm{al}^{34}$ reported increase in endogenous melatonin level after administration of prolonged exogenous melatonin in young and old people. Melatonin may provide feedback via high-affinity melatonin receptors in the $\mathrm{SCN}^{35,36}$ thus influencing the rhythm of its own production and other circadian rhythms too. ${ }^{14,37}$ The mechanism of protective effect of melatonin has been discussed by many authors. Being a lipophilic molecule, melatonin can effect intracellular MT1 and/MT2 receptors ${ }^{38}$ found in the cardiovascular system. ${ }^{39}$ The constrictive effect of melatonin can be explained by receptor-mediated decrease in the cyclic adenosine monophosphate levels ${ }^{40,41}$ and phosphatidylinositol-4, 5-bisphosphate hydrolysis. ${ }^{38}$ During initial observation of our study, hypertension was observed in maximum number of $\mathrm{CAD}$ subjects; this may be associated with disturbed neurotransmission in $\mathrm{SCN}^{42}$ which is the regulatory center for melatonin secretion ${ }^{43}$ and autonomic tone. ${ }^{44,45}$ Our findings implicate that melatonin influences central regulatory mechanisms involved in the BP control, as indicated by reported restored baroreflex responses ${ }^{45}$ decreased sympathetic output, ${ }^{46}$ and associated decreased HR or cardiac output with BP fall after melatonin administration ${ }^{14,47}$ in other studies. The mechanisms participating in central effect of melatonin are yet not completely known; however, several pathways are suggested by many authors. It could be hypothesized that the modulation of SCN activity by melatonin ${ }^{36,38}$ alters sympathetic tone and represents a protective mechanism against excessive sympathetic excitation. Thus, our studies suggest a protective role of melatonin in synchronization of impaired circadian pattern of BP in subjects with CAD. Normal ABPM is itself a strong predictor of enormous variability of BP and HR. Extent of hour-to-hour and day-to-day variability, 24 hours/7 days monitoring has emerged as an important tool of studying variability in $\mathrm{BP}$, which helps in prognosis of hypertension and white coat hypertension. We recognize that melatonin is of special interest, being an endogenous molecule that can be used in humans, and which is also safe. In the future, more experiments are required to study the effect of melatonin on cardiovascular system and elucidate the potential interactions between melatonin and the different classes of antihypertensive medicine in BP regulation. Since cardiovascular regulation is a complex mechanism which may not be solely regulated by melatonin, we will like to conclude that melatonin offers a protective role in subjects with dissynchronous circadian pattern of cardiac functions 
and could minimize the risk of various clinical events associated with BP rhythms.

\section{ACKNOWLEDGMENTS}

Authors would like to thank Prof Franz Halberg, Halberg Chronobiology center, University of Minnesota, for ABPM statistics help. Last but not least, the authors are grateful to all study subjects who participated so willingly and patiently for the duration of a long 1 year.

\section{REFERENCES}

1. Miller-Craig MW, Bishop CN, Raftery EB. Circadian variation of blood pressure. Lancet 1978 Apr;1(8068):795-797.

2. Drayer JI, Weber MA. Reproducibility of blood pressure values in normotensive subjects. Clin Exp Hypertens A 1985;7(2-3):417-422.

3. Pickering TG. Blood pressure measurement and detection of hypertension. Lancet 1994 Jul;344(8914):31-35.

4. Kurpesa M, Trzos E, Drozdz J, Bednarkiewicz Z, KrzemińskaPakuła M. Myocardial ischemia and autonomic activity in dippers and non-dippers with coronary artery disease: assessment of normotensive and hypertensive patients. Int J Cardiol 2002 May;83(2):133-142.

5. Brugger P, Marktl W, Herold M. Impaired nocturnal secretion of melatonin in coronary heart disease. Lancet 1995 Jun;345(8962):1408.

6. Dominguz-Rodriguez A, Abreu-Gonzalez P, SanchezSanchez JJ, Kaski JC, Reiter RJ. Melatonin and circadian biology in human cardiovascular disease. J Pineal Res 2010 Aug;49(1):14-22.

7. Portaluppi, F.; Smolensky, MH. Circadian rhythm and environmental determinants of blood pressure regulation in normal and hypertensive conditions. In: White WB, editor. Blood pressure monitoring in cardiovascular medicine and therapeutics. Totowa (NJ): Humana Press; 2000. pp. 79-118.

8. Sica, DA.; Wilson, DK. Sodium, potassium, the sympathetic nervous system, and the renin-angiotensin system: impact on the circadian variability in blood pressure. In: White WB, editor. Blood pressure monitoring in cardiovascular medicine and therapeutics. Totowa (NJ): Humana Press; 2000. pp. 171-190.

9. Halberg F, Ahlgren A, Haus E. Circadian systolic and diastolic hyperbaric indices of high school and college students. Chronobiologia 1984 Jul-Sep;11(3):299-309.

10. Lemmer, B. Cardiovascular chronobiology and chronopharmacology. In: Touitou Y, Haus E, editors. Biologic rhythms in clinical and laboratory medicine. Berlin: Springer-Verlag; 1992. pp. 418-427.

11. Linsell CR, Lightman SL, Mullen PE, Brown MJ, Causon RC. Circadian rhythms of epinephrine and norepinephrine in man. J Clin Endocrinol Metab 1985 Jun;60(6):1210-1215.

12. Lusardi P, Piazza E, Fogari R. Cardiovascular effects of melatonin in hypertensive patients well controlled by nifedipine: a 24-hour study. Br J Clin Pharmacol 2000 May;49(5):423-427.

13. Malpaux B, Migaud M, Tricoire H, Chemineau P. Biology of mammalian photoperiodism and the critical role of the pineal gland and melatonin. J Biol Rhythms 2001 Aug;16(4):336-347.

14. Halberg F, Cornélissen G, Wall D, Otsuka K, Halberg J, Katinas G, Watanabe Y, Halhuber M, Bohn TM, Delmore P, et al. Engineering and governmental challenge: 7-Day/24hour chronobiologic blood pressure and heart rate screening: part II. Biomed Instrum Technol 2002 May/Jun;36(3):183-197.

15. Zanoboni A, Forni A, Zanoboni-Muciaccia W, Zanussi C. Effect of pinealectomy on arterial blood pressure and food and water intake in the rat. J Endocrinol Invest 1978 Apr;1(2):125-130.

16. Domínguez-Rodríguez A, Abreu-González P, García MJ, Sanchez J, Marrero F, de Armas-Trujillo D. Decreased nocturnal melatonin levels during acute myocardial infarction. J Pineal Res 2002 Nov;33(4):248-252.

17. Sakotnik A, Liebmann PM, Stoschitzky K, Lercher $P$, Schauenstein K, Klein W, Eber B. Decreased melatonin synthesis in patients with coronary artery disease. Eur Heart J 1999 Sep;20(18):1314-1317.

18. Klein DC,WellerJL. Rapid light-induced decrease in pineal serotonin N-acetyltransferase activity. Science 1972 Aug;177(4048): 532-533.

19. Knutsson A. Health disorders of shift workers. Occup Med (Lond) 2003 Mar;53(2):103-108.

20. Sherwood A, Steffen PR, Blumenthal JA, Kuhn C, Hinderliter AL. Nighttime blood pressure dipping: the role of the sympathetic nervous system. Am J Hypertens 2002 Feb;15(2 Pt 1):111-118.

21. Hermida RC, Calvo C, Ayala DE, Soler R, Mojón A, López JE, Rodríguez M, Chayán L, Fontao MJ, Alonso I, et al. Prediction of cardiovascular events by ambulatory blood pressure and effects of chronotherapy: the MAPEC study. J Hypertens 2007;24(Suppl 4):S180.

22. Watanabe $Y$, Nishimura H, Sanaka S, Otsuka K, Ohkawa S. Does sodium sensitivity affect nocturnal blood pressure variation in outpatients with hypertension? Clin Exp Hypertens 2002 Jan-Feb;24(1-2):99-107.

23. Siegelova J, Fisher B, Havelkin A, Dusek J, Homoloka P, Vank P, Pohanka M, Mazek M, Cornellissen G, Halberg F. Circadian blood pressure variation analyzed from 7-day ambulatory blood pressure monitoring in patients with ischaemic heart disease. Scripta Med 2010;83(1):41-48.

24. Halberg F, Scheving LE, Lucas E, Cornélissen G, Sothern RB, Halberg E, Halberg J, Halberg F, Carter J, Straub KD, et al. Chronobiology of human blood pressure in the light of static (room restricted) automatic monitoring. Chronobiologia 1984 Jul-Sep;11(3):217-247.

25. Cornelissen, G.; Halberg, F. Chronomedicine. In: Armitage P, Colton T, editors. Encyclopedia of biostatistics. Vol. 1. Chichester: Wiley; 1998. pp. 642-649.

26. Hermida RC, Mojón A, Fernández JR, Alonso I, Ayala DE. The tolerance hyperbaric test: a chronobiologic approach for improved diagnosis of hypertension. Chronobiol Int 2002 Nov;19(6):1183-1211.

27. Fisher, RA. Statistical methods for research workers. 11th ed. Edinburgh: Oliver and 345 Boyd Ltd.; 1950.

28. Scheer FA, Van Montfrans GA, van Someren EJ, Mairuhu G, Buijs RM. Daily nighttime melatonin reduces blood pressure in male patients with essential hypertension. Hypertension 2004 Feb;43(2):192-197.

29. Birau N, Peterssen U, Meyer C, Gottschalk J. Hypotensive effect of melatonin in essential hypertension. IRCS Med Sci 1981 Jan;9:906.

30. Frattola A, Parati G, Cuspidi C, Albini F, Mancia G. Prognostic value of 24-hour blood pressure variability. J Hypertens 1993 Oct;11(10):1133-1137. 
31. Rechciński T, Trzos E, Wierzbowska-Drabik K, KrzeminskaPakula M, Kurpesa M. Melatonin for nondippers with coronary artery disease: assessment of blood pressure profile and heart rate variability. Hypertens Res 2010 Jan;33(1):56-61.

32. Halberg, F.; Kenner, T.; Siegelova, J.; editors. Proceedings, symposium, chronobiological analysis in pathophysiology of cardiovascular system. Brno: Masaryk University; 2003. p. 186.

33. Scheer FA, Ter Horst GJ, van Der Vliet J, Buijs RM. Physiological and anatomic evidence for regulation of the heart by suprachiasmatic nucleus in rats. Am J Physiol Heart Circ Physiol 2001 Mar;280(3):H1391-H1399.

34. Laakso M, Porkka-Heiskanen T, Alila A, Stenberg D, Johansson G. Fibrinogen as a risk factor for coronary heart disease and mortality in middle-aged men and women. The Scottish Heart Health Study. Eur Heart J 1997;19(1)55-62.

35. Weaver DR, Reppert SM. The Mella melatonin receptor gene is expressed in human suprachiasmatic nuclei. Neuroreport 1996 Dec;8(1):109-112.

36. Reppert SM, Weaver DR, Rivkees SA, Stopa EG. Putative melatonin receptors in a human biological clock. Science 1988 Oct;242(4875):78-83.

37. Bothorel B, Barassin S, Saboureau M, Perreau S, VivienRoels B, Malan A, Pévet P. Exogenous melatonin increases the amplitude of the pineal melatonin secretion by a direct action on the circadian clock in the rat. Eur J Neurosci 2002; 16:1-10

38. Dubocovich ML. Melatonin receptors: are there multiple subtypes? Trends Pharmacol Sci 1995 Feb;16(2):50-56.

39. Ekmekcioglu C, Haslmayer P, Philipp C, Mehrabi Mr, Glogar Hd, Grimm M, Leibetseder VJ, Thalhammer T, Marktl W. Expression of the MT1 melatonin receptor subtype in human coronary arteries. J Recept Signal Transduct Res 2001 Feb;21(1):85-91.

40. Capsoni S, Viswanathan M, De Oliveira AM, Saavedra JM. Characterization of melatonin receptors and signal transduction system in rat arteries forming the circle of Willis. Endocrinology 1994 Jul;135(1):373-378.

41. Witt-Enderby PA, Dubocovich ML. Characterization and regulation of the human Ml1A melatonin receptor stably expressed in Chinese hamster ovary cells. Mol Pharmacol 1996 Jul;50(1):166-174.

42. Goncharuk VD, Heerikhuize JV, Dai JP, Swaab DF, Buijs RM. Neuropeptide changes in the suprachiasmatic nucleus in primary hypertension indicate functional impairment of the biological clock. J Comp Neurol 2001 Mar;431(3):320-330.

43. Klein, DC.; Moore, RY.; Reppert, SM.; editors. The suprachiasmatic nucleus. The Mind's Clock. Oxford (NY): Oxford University Press; 1992. p. xvi.

44. Scheer FA, van Doornen LJ, Buijs RM. Light and diurnal cycle affect human heart rate: possible role for the circadian pacemaker. J Biol Rhythms 1999 Jun;14(3):202-212.

45. Girouard H, Denault C, Chulak C, de Champlain J. Treatment by $\mathrm{N}$-acetylcysteine and melatonin increases cardiac baroreflex and improves antioxidant reserve. Am J Hypertens 2004 Oct;17(10): 947-954.

46. K-Laflamme A, Wu L, FoucartS, de Champlain J. Impaired basal sympathetic tone and $\alpha 1$-adrenergic responsiveness in association with the hypotensive effect of melatonin in spontaneously hypertensive rats. Am J Hypertens 1998 Feb;11(2):219-229.

47. Arangino S, Cagnacci A, Angiolucci M, Vacca AM, Longu G, Volpe A, Melis GB. Effects of melatonin on vascular reactivity, catecholamine levels, and blood pressure in healthy men. Am J Cardiol 1999 May;83(9):1417-1419. 